\title{
Assessment of the Impact of Wastewater Sachets on the Bearing Capacity of Phyllitic Soil
}

\author{
Mr. Desmond-Luke M. Anglaaere \\ PG student, Civil Engineering, \\ Faculty of Civil Engineering and Mechanics, \\ Jiangsu University, China.
}

\author{
Dr. Enquan Zhou \\ Lecturer, Civil Engineering Department, \\ Faculty of Civil Engineering and Mechanics, \\ Jiangsu University, China.
}

\author{
Mr. Prince Mashavave \\ PG student, Civil Engineering, \\ Faculty of Civil Engineering and Mechanics, \\ Jiangsu University, China.
}

\begin{abstract}
Soil improvement is a major factor considered when dealing with weak soils for engineering purposes. This report presents the various tests conducted on fiber-reinforced soil with varying fiber content and different aspect ratios. Strips of wastewater sachets were used as a reinforcement material to perform the strength test on the soil. Several Compaction and California Bearing Ratio (CBR) tests were conducted on randomly reinforced soil by alternating the aspect ratio or sizes of plastic strips. The aspect ratios used were $15 \times 10 \mathrm{~mm}, 15 \times 20 \mathrm{~mm}$ and $15 \times 30 \mathrm{~mm}$. The CBR value obtained for the unreinforced soil was $6.85 \%$. The CBR values obtained for the reinforced soil with the plastic fiber of sizes, $15 \times 10 \mathrm{~mm}, 15 \times 20 \mathrm{~mm}$, and $15 \times 30 \mathrm{~mm}$ were $9.31 \%, 16.91 \%$, and $17.57 \%$ respectively. The CBR test results showed that the reinforcement benefit increased with an increase in aspect ratio. Hence, appropriately cut strips of wastewater sachets with optimum sizes would prove useful for soil improvement if mixed with locally available soils in an appropriate quantity. The proposed technique is recommended for embankment/road construction, industrial yards among others.
\end{abstract}

Keywords: CBR, Compaction, Phyllitic soil, Wastewater sachets, Aspect ratio

\section{INTRODUCTION}

Soil is a fundamental material used in every type of construction. The soil used for construction must always be competent enough to withstand the load imposed on it. However, soil types like clay, silt, and organic soils are thought to be of poor quality soils for construction. These varieties of soil are often encountered during construction which is usually excavated and transported to dump sites at a high cost. It has been shown that the geotechnical properties of such soils can be improved for use in construction by numerous techniques such as the addition of Portland cement, lime, bitumen, fly ash, plastic waste, etc. Studies have shown that plastic wastes when mixed with soil behave like fiber-reinforced soil. The mixture of these materials with the soil mass tends to cut back the probabilities of developing potential planes of weakness and the strength, stiffness, ductility, and toughness of the soil are improved to some extent. Phyllitic soils are soils that are derived from the weathering of phyllite (a metamorphic rock). These soils contain predominant clay and silt particles and are classified as weak for construction. Examination of the geotechnical and microstructural characteristics of this soil type was conducted to study its influence on the instability of high slopes indicted failures associated with this type of soil [1]. Recent economic and economic growth has led to the construction of new structures and buildings in many parts of the world. During these constructions, there is the possibility of encountering weak soils along the road corridor which may have to be completely removed or improved upon. In Ghana, wastewater sachets are often littered around by individuals. These end up choking gutters and polluting the environment. These choked gutters cause floods during a heavy downpour, therefore, posing threats to human life. Also, the increase in population has led to the production of more plastic products for the satisfaction of human needs hence the pollution by plastic waste is on the rise. To ensure economic and ecofriendly construction, many pieces of research have been conducted to explore the possible ways waste materials can be useful in construction. Sing and Mittal [2] Researched the use of plastic strips for soil stabilization. Different contents of the Strips of different proportions were added to the soil. The optimum percentage of plastic strips needed for stabilization was obtained at the end of the experiment. Raw plastic bottles were used by $[3,4]$ to stabilize the soil. They studied its effect on the mechanical properties of the soil. A plate loading test and a California bearing test were conducted. The result produced a significant effect on the enhancement of soil strength. Furthermore, there is a wide range of plastics being used for the stabilization process. The use of a Highly Dense Polyethylene (HDPE) plastic in the stabilization process yielded positive results [5,6],[7]. The addition of optimum quantities of the plastic strips improved the strength properties of the soil. Sing et al [8] Conducted an experiment using scrape rubber tire to stabilize clay soil. A percentage of $0.05 \%, 0.06 \%, 0.7 \%, 0.8 \%, 0.9 \%$ and $1 \%$ of tire chips were mixed in clay for the conduction of a CBR test. There were improvements in the shear strength, ductility, toughness, and isotropy in the soil.

In this research, wastewater sachets will be used as the plastic strips. A series of CBR tests will be conducted with varying percentages of the plastic strips. The result will reveal the significance of the use of plastics in the stabilization of soil. The use of waste materials for the improvement of soil has been on the rise. This phenomenon came up as the need to employ ways of dealing 
with challenges caused by waste materials. The control of plastic waste has been a major ecological challenge due to its biodegradable nature hence needs effective management interventions. The engineering behavior of soil reinforced by plastic strips was noted to be significantly improved [9]. Dachowski [10] investigated the use of waste materials in the construction industry. Foam glass and high-impact polystyrene were used as modifiers of the basic construction materials. The focus of the research was to analyze the compressive strength, water absorption, bulk density, and the construction of structural material. Based on the studies, the additives had a significant influence on the properties of cement mortars. It was concluded that the use of high-impact polystyrene and foam glass can be considered as a useful way of utilization waste. Further analysis of the use of plastics by $[11,12]$ and $[13,14]$ proved the effective use of tire scraps in the stabilization process. The addition of different proportions of the tire scraps improved the strength properties of the soil at an optimum quantity of the tire scraps. More so, Kalumba and Chebet [15] evaluated the use of shopping bags in stabilizing sandy soil. The shopping bags waste were cut into strips of aspect ratios $15 \mathrm{~mm} \times 6 \mathrm{~mm}$ and $45 \mathrm{~mm} \times 18 \mathrm{~mm}$ and added to soil at a constant proportion of $0.3 \%$ by weight. A number of direct shear tests were conducted on the soil and plastic mixture which resulted in an improvement of the shear strength property of the soil. Polyethylene terephthalate fibers extracted from recycled plastic bottles were mixed with cement to improve the engineering properties of uniform fine sand [16]. The fibers were cut into varying lengths up to $36 \mathrm{~mm}$ and cement was from $0 \%$ to $7 \%$ by weight. The results indicated a significant improvement in the peak and ultimate strength of both cemented and uncemented soil and also cut down the brittleness of the cemented sand. Plastic wastes have been incorporated into many recent construction projects through material stabilization. The use of waste rubber in construction includes the stabilization of materials such as cement-based concrete, asphalt concrete, and granular materials for earth structures [17]. An investigation was conducted by Muntohar [18] to analyze the effect of plastic waste on the Strength of Lime-Rice Husk Ash stabilized clay soil. In this research, the clay was already stabilized by lime and rice husk. However, plastic fibers were added to investigate its effect on the compressive and split strength of the soil. This resulted in a significant increase in the unconfined compressive strength and tensile-split strength of the clay soil. Most researches conducted using polythene fibers focused more on the proportion of the strips and less on the aspect ratio of the strips. This research seeks to elaborate on the use of plastic strips with different aspect ratios.

This paper presents a study on the use of wastewater sachets, a popular plastic product used in Ghana, to improve upon the quality of phyllitic soil for construction. Phyllitic soils are weak soils that are predominately composed of silt and clay. The use of the wastewater sachet for such a purpose would also have a positive impact on the environment as this would reduce pollution to some extent. This paper, therefore, seeks to analyze the influence of wastewater sachets in the stabilization of phyllitic soil.

\section{MATERIALS AND METHODOLOGY}

Phyllitic Soil: This experiment was conducted using phyllitic soil obtained from a test pit. A test pit was dug at a depth of 1.5 meters $(\mathrm{m})$ to obtain fresh soil from the ground void of debris or any form of impurities.

Wastewater sachets: The water sachets were collected from recycling bins for this experiment. This material is added to soil in a form of strips with different aspect ratios.

Various tests were carried out on the soil samples based on the BS code 1377 of 1990 to obtain the required data for analysis. Among the tests conducted were the index property test and the strength test.

The index property test include;

- Moisture Content Determination.

- Atterberg's Limit Test.

- Specific Gravity Test.

- Sieve Analysis.

The strength test conducted include;

- Compaction Test.

- California Bearing Ratio Test.

The main focus of the test is to determine the effect of the wastewater sachet on the strength of the soil sample. A compaction test was conducted according to the ASTM code to determine the maximum dry density and optimum moisture content of the soil. 


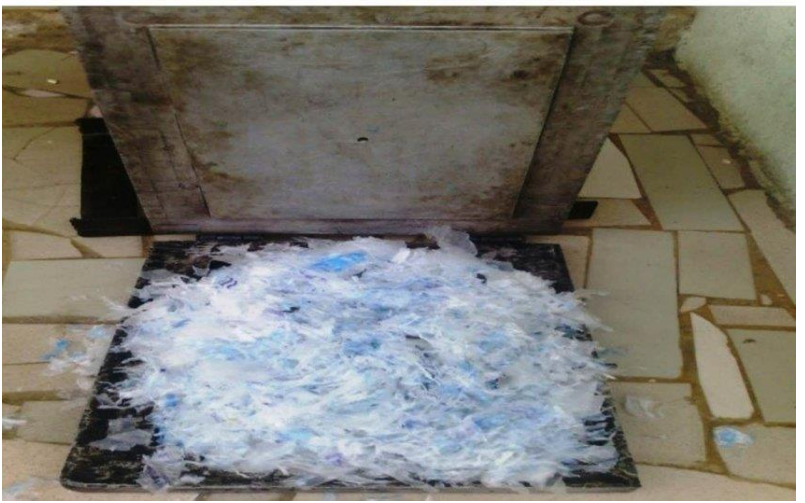

Figure 1a. Pulverized water sachets

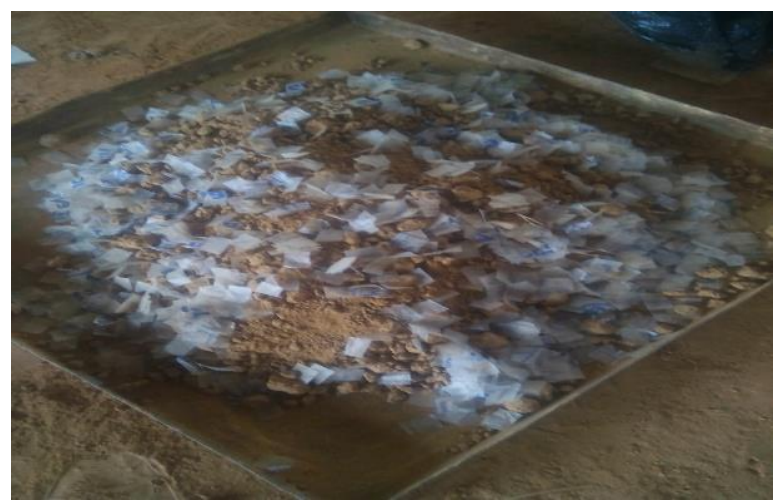

Figure 1b. Soil mixed with waste water sachet

\section{RESULTS}

Atterberg's Limits Test

At the end of the test, a liquid limit chart was generated with the number of blows plotted against moisture content. The plotted values are shown in Table 1. From the chart, (Fig 2), the liquid limit was determined and used to calculate the plasticity index. With the plasticity index, the inference was made from the plasticity chart as shown in Fig 3.

Table 1 Plotted Values for Liquid Limit

\begin{tabular}{|l|l|}
\hline NUMBER OR BLOWS & MOISTURE CONTENT \\
\hline 41.0 & 22.1 \\
\hline 32.0 & 21.4 \\
\hline 22.0 & 22.1 \\
\hline 11.0 & 26.3 \\
\hline
\end{tabular}

LIQUID LIMIT CHART

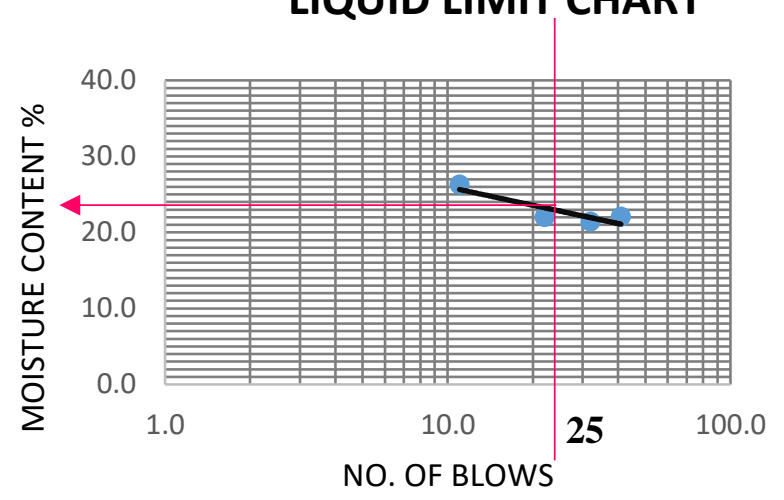

Fig 2. Liquid Limit Chart

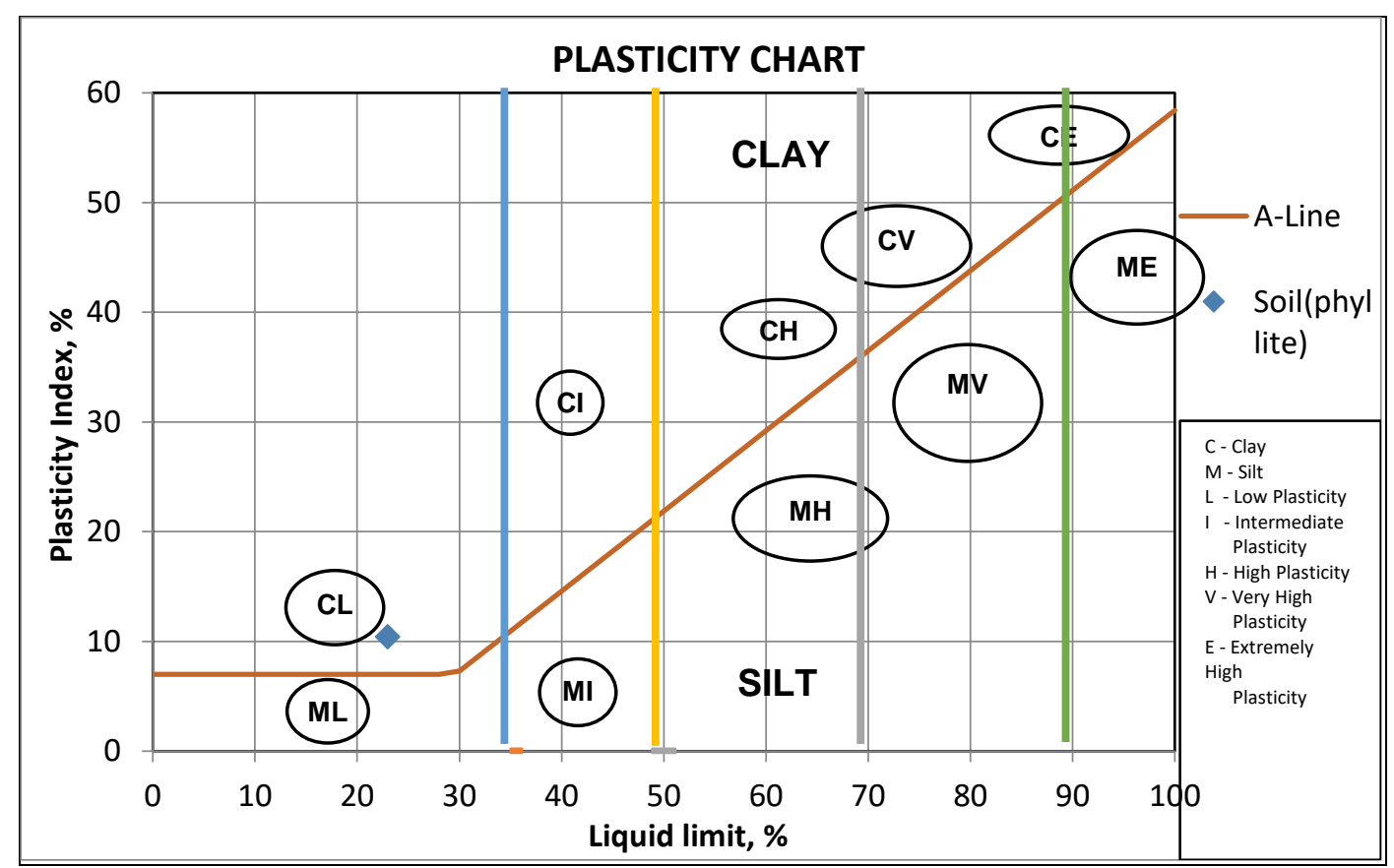

Fig 3 Plasticity Chart (after Casagrande 1948 [19]). 
Specific Gravity Test

From the specific gravity test, the average specific gravity of the soil was obtained from the results shown in Table 2

\begin{tabular}{|c|c|c|}
\hline \multirow{2}{*}{$\begin{array}{l}\text { Specimen ID } \\
\text { Pycnometer Bottle No. }\end{array}$} & \multicolumn{2}{|c|}{ Phyllite } \\
\hline & $\mathbf{C}$ & $\mathbf{B}$ \\
\hline Mass of empty Pycnometer + stopper & 21.8 & 20.4 \\
\hline Mass of empty Pycnometer + soil & 31.8 & 30.4 \\
\hline Mass of empty Pycnometer + soil + Liquid (m3) & 66.4 & 66.8 \\
\hline Mass of empty Pycnometer + Liquid & 61 & 59 \\
\hline Specific Gravity, $\rho s=[((\mathrm{m} 2-\mathrm{m} 1)) /((\mathrm{m} 4-\mathrm{m} 1)-(\mathrm{m} 3-\mathrm{m} 2))] \times \rho \mathbf{L}$ & 1.78 & 3.71 \\
\hline Average Specific Gravity & 2.75 & \\
\hline
\end{tabular}

At the end of the test, the obtained specific gravity was used to classify the soil according to the specific gravity ranges

\section{Compaction}

From the compaction test, a graph of dry density against water content was plotted.

\section{COMPACTION GRAPH}

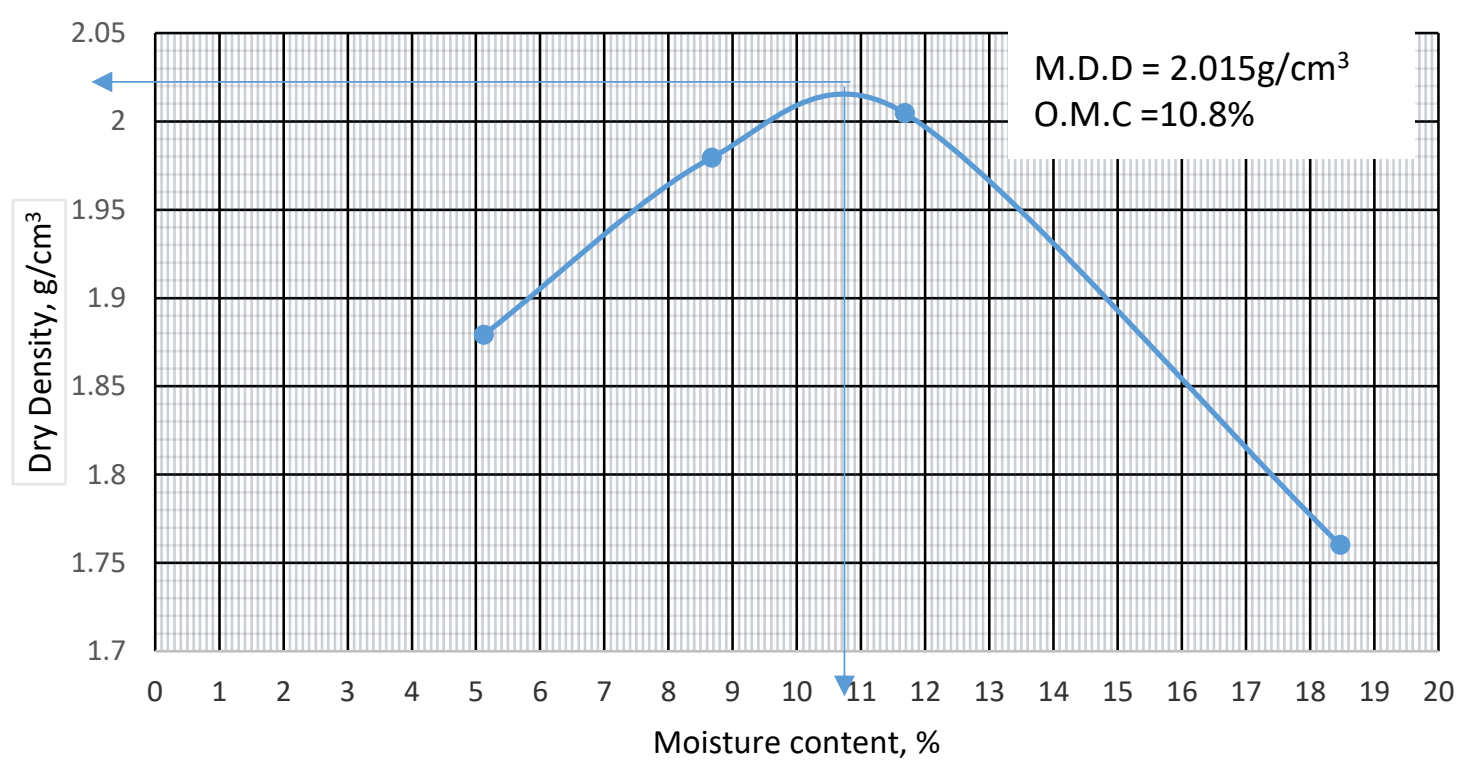

Fig 4 Compaction Curve for the Phyllitic Soil.

At the end of the test, a maximum dry density of $2.015 \mathrm{~g} / \mathrm{cm}^{3}$ and an optimum moisture content of $10.8 \%$ were obtained.

CBR Test

The test was conducted on the same soil first with no plastic strip followed by soil with different aspect ratios of plastic strip thus $(15 \times 10 \mathrm{~mm}),(15 \times 20 \mathrm{~mm})$, and $(15 \times 30 \mathrm{~mm})$. The results are shown below. Also, a load penetration curve is illustrated in figure

Table 4 Phyllitic Soil 0\% Plastic Strip

\begin{tabular}{|l|l|l|l|}
\hline PEN. (mm) & READING & LOAD $(\mathbf{k N})$ & CBR \% \\
\hline 0.5 & 5.0 & 214.0 & \\
\hline 1.0 & 8.0 & 342.4 & \\
\hline 1.5 & 11.2 & 479.4 & \\
\hline 2.0 & 14.5 & 620.6 & \\
\hline 2.5 & 18.0 & 770.4 & $\mathbf{5 . 8}$ \\
\hline 3.0 & 21.1 & 903.1 & \\
\hline 3.5 & 24.2 & 1035.8 & \\
\hline 4.0 & 27.0 & 1155.6 & \\
\hline 4.5 & 30.0 & 1284.0 & \\
\hline 5.0 & 32.0 & 1369.6 & $\mathbf{6 . 9}$ \\
\hline 5.5 & 35.0 & 1498.0 & \\
\hline 6.0 & 48.0 & 2054.4 & \\
\hline
\end{tabular}

Table 5 Phyllitic Soil with $0.5 \%$ Plastic Strip of AR $(15 \times 10 \mathrm{~mm})$

\begin{tabular}{|l|l|l|l|}
\hline PEN. (mm) & READING & LOAD $(\mathbf{k N})$ & CBR \% \\
\hline 0.5 & 4 & 171.2 & \\
\hline 1.0 & 10 & 428 & \\
\hline 1.5 & 14.8 & 633.44 & \\
\hline 2.0 & 19.2 & 821.76 & \\
\hline 2.5 & 23.8 & 1018.64 & $\mathbf{7 . 7 2}$ \\
\hline 3.0 & 28 & 1198.4 & \\
\hline 3.5 & 32 & 1369.6 & \\
\hline 4.0 & 36 & 1540.8 & \\
\hline 4.5 & 39.8 & 1703.44 & \\
\hline 5.0 & 43.5 & 1861.8 & $\mathbf{9 . 3 1}$ \\
\hline 5.5 & 47 & 2011.6 & \\
\hline 6.0 & 50.4 & 2157.12 & \\
\hline
\end{tabular}


Table 6 Phyllitic Soil with $0.5 \%$ Plastic Strip of AR (15X20mm)

\begin{tabular}{|l|l|l|l|}
\hline PEN. $(\mathbf{m m})$ & READING & LOAD $(\mathbf{k N})$ & CBR \% \\
\hline 0.5 & 2.0 & 85.6 & \\
\hline 1.0 & 7.0 & 299.6 & \\
\hline 1.5 & 16.0 & 684.8 & \\
\hline 2.0 & 29.0 & 1241.2 & \\
\hline 2.5 & 41.0 & 1754.8 & $\mathbf{1 3 . 3}$ \\
\hline 3.0 & 49.0 & 2097.2 & \\
\hline 3.5 & 55.0 & 2354.0 & \\
\hline 4.0 & 61.0 & 2610.8 & \\
\hline 4.5 & 70.0 & 2996.0 & \\
\hline 5.0 & 79.0 & 3381.2 & $\mathbf{1 6 . 9}$ \\
\hline 5.5 & 86.2 & 3689.4 & \\
\hline 6.0 & 91.0 & 3894.8 & \\
\hline
\end{tabular}

Table 7 CBR results for Phyllitic Soil with $0.5 \%$ Plastic Strip of AR (15X30mm)

\begin{tabular}{|l|l|l|l|}
\hline PEN. (mm) & READING & LOAD $(\mathbf{k N})$ & CBR \% \\
\hline 0.5 & 24.0 & 1027.2 & \\
\hline 1.0 & 31.0 & 1326.8 & \\
\hline 1.5 & 37.0 & 1583.6 & \\
\hline 2.0 & 43.0 & 1840.4 & \\
\hline 2.5 & 48.0 & 2054.4 & $\mathbf{1 5 . 6}$ \\
\hline 3.0 & 53.0 & 2268.4 & \\
\hline 3.5 & 58.0 & 2482.4 & \\
\hline 4.0 & 64.0 & 2739.2 & \\
\hline 4.5 & 72.0 & 3081.6 & \\
\hline 5.0 & 82.1 & 3513.9 & $\mathbf{1 7 . 6}$ \\
\hline 5.5 & 89.0 & 3809.2 & \\
\hline 6.0 & 95.0 & 4066.0 & \\
\hline
\end{tabular}

\section{Load penetration curve}

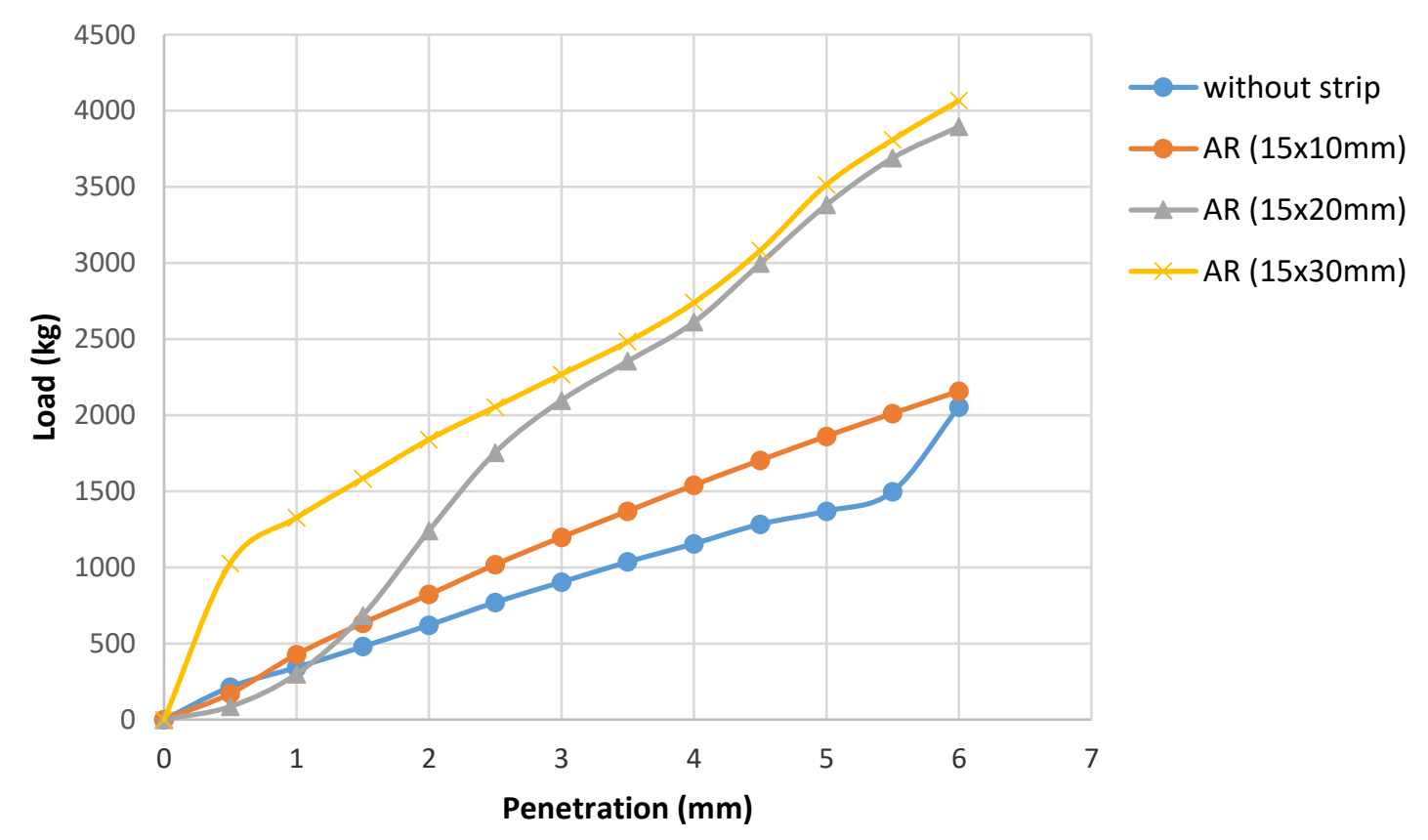

Figure 5 CBR Curves for Various Aspect Ratios (AR) of Plastic Mixed with the Soil. 


\section{DISCUSSION OF RESULTS}

From the index property test conducted, the soil has a specific gravity of 2.75 which from the specific gravity chart indicates it contains silt and clay. It has a liquid limit of 23.0, a plastic limit of 12.6, and a plasticity index of 10.4. According to the plasticity chart, the soil was classified as "CL" (clayey with low plasticity). The maximum dry density and optimum water content as determined by the compaction test were $2.015 \mathrm{~g} / \mathrm{cm}^{3}$ and $10.8 \%$. This means that beyond the optimum moisture content the dry unit weight of the soil would reduce.

After completion of each CBR test, the specimen was dissected and the strips were examined. Many of the strips showed elongation, thinning, and a clear impression of soil particles. Apparently, as the soil sheared during penetration, the strips fixed in the soil by friction, elongated, and together provided strength against the deformation. The CBR test was conducted with varying aspect ratios at the same strip content thus $0.5 \%$. The results indicated an increase in the piston load upon the uniform mixture of the plastic strips with the soil. It is also evident from the results that the inclusion of waste plastic increased the CBR value appreciably. At $0 \%$ plastic strip content, the CBR value of the soil at $2.5 \mathrm{~mm}$ and $5.0 \mathrm{~mm}$ penetration was found to be $5.84 \%$ and $6.85 \%$ respectively. The CBR value was increased to $7.72 \%$ and $9.31 \%$ respectively when the soil was reinforced with $0.5 \%$ waste plastic strips having an aspect ratio $(15 \times 10 \mathrm{~mm})$. Further increase in aspect ratio without changing the strip content again enhanced the CBR value to $13.29 \%$ and $16.91 \%$ for (AR: $15 \times 20 \mathrm{~mm}$ ) and CBR values of $15.56 \%$ and $17.57 \%$ for (AR: $15 \times 30 \mathrm{~mm}$ ) respectively. The maximum CBR value obtained was $15.56 \%$ and $17.57 \%$ respectively when $0.5 \%$ waste plastic strip content having an aspect ratio $(15 \times 30 \mathrm{~mm})$ was mixed with the soil. This reveals that at AR $(15 \times 30 \mathrm{~mm})$ for $0.5 \%$ strip content gives us the maximum bearing strength.

\section{CONCLUSIONS}

The possibility of reinforcing soil with strips of plastic waste was investigated in this study. Strips of water sachet wastes were mixed with soil and tested to determine CBR values; maximum load-carrying capacity of subsoil. The result analysis showed that reinforcing soil with waste plastic strips enhances its strength. Inferring from the results obtained, the following conclusions were made.

- The CBR value obtained without plastic strips was $6.85 \%$

- The CBR value obtained while using a plastic strip of Aspect Ratio (AR) of $15 \times 10 \mathrm{~mm}$ was $9.31 \%$

- The CBR value obtained while using a plastic strip of Aspect Ratio (AR) of $15 \times 20 \mathrm{~mm}$ was $16.91 \%$

- The CBR value obtained while using a plastic strip of Aspect Ratio (AR) of $15 \times 30 \mathrm{~mm}$ was $17.57 \%$

- The addition of the plastic strips to local soil increases the CBR.

- The maximum improvement in CBR is obtained while using $0.5 \%$ of plastic strips having an aspect ratio (15x30 mm).

- The reinforcement benefit increases with an increase in Aspect Ratio (AR).

The reinforcement benefit increased with an increase in AR, therefore, I can conclude that appropriately cut strips of wastewater sachets with optimum sizes would prove useful for soil improvement if mixed with locally available soils in an appropriate quantity.

I recommend that further studies must be conducted;

\section{RECOMMENDATION}

- To optimize the size and shape of strips and increasing the percentage content.

- To assess the durability and aging of the strip.

- To further explore the engineering properties of the soil that can be enhanced.

[1] M. Saberian and M. A. Rahgozar, "Geotechnical properties of peat soil stabilised with shredded waste tyre chips in combination with gypsum, lime or cement," Mires Peat, vol. 18, 2016, doi: 10.19189/MaP.2015.OMB.211.

[2] K. Singh and A. Mittal, "Soil Stabilisation Using Plastic Waste," Lect. Notes Civ. Eng., vol. 32, pp. 91-96, 2019, doi: 10.1007/978-981-13-7017-5_10.

[3] S. Saravanan and B. J. Ravindraraj, "Soil stabiliisation using raw plastic bottles," Int. J. Civ. Eng. Technol., vol. 9, no. 4, 2018 pp. 812-815.

[4] R. B. Kassa, T. Workie, A. Abdela, M. Fekade, and M. Saleh, "Soil Stabilization Using Waste Plastic Materials," vol. D, pp. 55-68, 2020, doi: 10.4236/ojce.2020.101006

[5] M. Neopaney, K. Wangchuk, S. Tenzin, Ks. Chamberlin, and A. Professor, "Stabilization of Soil by Using Plastic Wastes," Int. J. Emerg. trends Eng. Dev., vol. 2, no. 2, 2012, pp. 461-466.

[6] T. Divya et al., "Experimental Analysis of Stabilization of Soil by using Plastic Waste," no. 2, 2015, pp. 371-376.

[7] A. K. Choudhary, J. N. Jha, and K. S. Gill, "a Study on Cbr Behavior of Waste Plastic Strip Reinforced Soil," Emirates J. Eng. Res., vol. 15, no. 1, 2010, pp. 51-57.

[8] S. Singh, U. Dhiman, and R. Sharma, "Soil Stabilization using Scrap Rubber Tyre," Int. Res. J. Eng. Technol., 2017, pp. 3157-3161.

[9] P. Bhattarai, B. Kumar, K. Santosh, T. C. Manikanta, and K. Tejeswini, "Engineering Behavior of Soil Reinforced With Plastic Strips," Int. J. Civ. , Struct., Environ. Infrastruct. Eng. Res. Dev., vol. 3, no. 2, 2013, pp. 2249-6866.

[10] R. Dachowski and P. Kostrzewa, "The Use of Waste Materials in the Construction Industry," in Procedia Engineering, 2016, vol. 161, pp. 754-758, doi: $10.1016 /$ j.proeng.2016.08.764.

[11] S. Akbulut, S. Arasan, and E. Kalkan, "Modification of clayey soils using scrap tire rubber and synthetic fibers," Appl. Clay Sci., vol. 38, no. 1-2, pp. 23-32, Dec. 2007, doi: 10.1016/j.clay.2007.02.001.

[12] J. S. Yadav and S. K. Tiwari, "Effect of waste rubber fibres on the geotechnical properties of clay stabilized with cement," Appl. Clay Sci., vol. 149, 2017, doi: 10.1016/j.clay.2017.07.037.

[13] Q. Ma, Q. Deng, J. Mou, S. Yang, and X. Zhang, "Large-Scale Direct Shear Test on Scrap Tire Strip Reinforced Brick Powder," Adv. Civ. Eng., vol. 2019, 2019, doi: 10.1155/2019/6046037. 
[14] M. D. V Zutting, “Soil Stabilization by using Scrap Tire Rubber," vol. 9, no. 06, 2020, pp. 1382-1388.

[15] D. Kalumba and F. C. Chebet, "Utilisation of polyethylene (plastic) shopping bags waste for soil improvement in sandy soils," 18th Int. Conf. Soil Mech. Geotech. Eng. Challenges Innov. Geotech. ICSMGE 2013, vol. 4, 2013, pp. 3223-3226.

[16] N. C. Consoli, J. P. Montardo, P. D. M. Prietto, and G. S. Pasa, "Engineering Behavior of a Sand Reinforced with Plastic Waste," J. Geotech Geoenvironmental Eng., vol. 128, no. 6, pp. 462-472, Jun. 2002, doi: 10.1061/(asce)1090-0241(2002)128:6(462).

[17] A. Mohajerani et al., "Recycling waste rubber tyres in construction materials and associated environmental considerations: A review," Resources, Conservation and Recycling, vol. 155. Elsevier B.V., 01-Apr-2020, doi: 10.1016/j.resconrec.2020.104679.

[18] a. S. Muntohar, "Influence of Plastic Waste Fibers on the Strength of Lime-Rice," Civ. Eng. Dimens., vol. 11, no. 1, 2009, pp. 32-40

[19] "Casagrande, A. (1948) Classification and Identification of Soils. Transactions of the American Society of Civil Engineers, 113, 901-930. - References - $\quad$ Scientific Research Publishing."'[Online].Available:https://www.scirp.org/(S(351jmbntvnsjt1 aadkposzje))/reference/ReferencesPapers.aspx?ReferenceID=2205851. [Accessed: 23-Dec-2020]. 